\title{
ANTIOXIDANT PROPERTIES AND POTENTIALITY OF SILVER NANOPARTICLES BIOSYNTHESIS OF THIRTY-FIVE EDIBLE BANGLADESHI FRUITS
}

\author{
HM Iftekhar Alam, Anirban Biswas, M Zakir Hosen, \\ M Rabiul Islam and Sheikh Julfikar Hossain* \\ Biotechnology and Genetic Engineering Discipline, Khulna University, \\ Khulna 9208, Bangladesh
}

Keywords: Antioxidant, Fruits, Polyphenols, Reducing power, Nanoparticles

\begin{abstract}
A comparison of total polyphenols (TP) and flavonoids (TF) contents, antioxidant activity, and silver nanoparticles (AgNPs) biosynthesis potentiality of 35 common edible fruits in Bangladesh were studied. Among the fruits, Emblica officinalis showed the highest content of TP (89 mg gallic acid equivalent (GAE)/g powder), reducing power (OD, 1.98 at $1 \mathrm{mg}$ powder/ml), and 2,2-diphenyl-1-picrylhydrazyl (DPPH)-free radical scavenging activity $(95.6 \%$ at $0.5 \mathrm{mg}$ powder $/ \mathrm{ml})$ whereas the highest content $(17.3 \mathrm{mg}$ (+)-catechin equivalent (CE)/g powder) of TF was recorded in Garcinia cowa. The inhibitory concentration $50\left(\mathrm{IC}_{50}\right)$ for DPPH-free radical scavenging of Annona reticulata, E. officinalis, G. cowa, Phoenix sylvestris, Psidium guajava and Syzygium cumini were 180, 21.8, 172, 188.9, 162.4 and $176.2 \mu \mathrm{g}$ powder/ml, respectively. Litchi chinensis showed the highest total antioxidant capacity ( $79 \mathrm{mg}$ GAE/g powder) followed by E. officinalis ( $69 \mathrm{mg} \mathrm{GAE} / \mathrm{g}$ powder). The fruits showed a very strong correlation $\left(\mathrm{r}^{2}=0.99\right)$ between TP and reducing power. $P$. guajava showed the highest potentiality (OD, 0.74 at $10 \mathrm{mg}$ powder/ml) in the biosynthesis of AgNPs followed by $S$. cumini, A. reticulata and P. sylvestris. Therefore, most potential five fruits should be graded as E. officinalis $>S$. cumini $>$ P. guajava $>$ A. reticulata $>$ P. sylvestris.
\end{abstract}

\section{Introduction}

Fruits provide various health-promoting dietary components. Among these components, antioxidants are the most important because they give up their electrons to neutralize the atoms and molecules which have unpaired electrons as called free radicals. Excess amount of free radicals initiates pathogenesis of various metabolic diseases including cancer, diabetes, cardiovascular diseases, pulmonary diseases, inflammations and aging (Kozyrev and Slutsky 2010, Hekimi et al. 2011). Therefore, it is indispensable to maintain a delicate balance between free radicals and antioxidants in the human body. Bangladesh produces various types of edible fruits which contribute at least, a part of the nutritional demand of her population in addition to promoting health through bioactive components.

Cluster of silver atoms forms silver nanoparticles (AgNPs) that fall 1 to $100 \mathrm{~nm}$ in diameter. At present, AgNPs are popular in the preparation of various products such as medicine, foods, soaps, shampoos, toothpastes, plastics, textiles etc. AgNPs that are synthesized for use in foods and healthcare must be free from toxic agents. Hence, components of edible fruits with strong reducing capacity should be the choice for the biosynthesis of AgNPs. Ahmed et al. (2016) showed superior effects of biosynthesized AgNPs over chemically synthesized ones.

Antioxidant and health-promoting activities of different solvent extracts of some Bangladeshi fruits have been reported (Hossain et al. 2008, 2013, 2017). In a single report, antioxidant activity and biosynthesis potentiality of AgNPs of as many as 35 edible fruits of Bangladesh were not

\footnotetext{
*Author for correspondence: <sjhossain_ku@yahoo.com>, <sjhossainbgeku@gmail.com>.
} 
compared. Since antioxidants are reducing agents, they use the same molecular mechanisms for the biosynthesis and stabilizing of AgNPs. In this study, the mixture of ethanol and methanol (1 : 1) was used as an extraction solvent of the fruits and compared their polyphenols and flavonoids contents, antioxidant activity, and potentiality of AgNPs biosynthesis.

\section{Materials and Methods}

The mature fruits of Aegle marmelos L. (wood apple), Ananas sativus L. (pineapple), Annona reticulata L. (custard apple), Artocarpus heterophyllus Lam. (jackfruit), Artocarpus lacucha Buch.-Ham. (monkey fruit), Averrhoa bilimbi L. (bilimbi), Averrhoa carambola L. (star fruit), Baccaurea ramiflora Lour. (burmese grape), Borassus flabellifer L. (palm), Carica papaya L. (papaya), Carissa carandas L. (green karanda), Citrus aurantifolia L. (lime), Citrus maxima Merr. (pomelo), Cocos nucifera L. (coconut), Dillenia indica L. (elephant apple), Dimocarpus longan Lour. (longan), Diospyros blancoi L. (velvet apple), Emblica officinalis L. (indian gooseberry), Ficus carica L. (fig), Garcinia cowa Roxb. (mangosteen), Limonia acidissima L. (sour wood apple), Litchi chinensis Sonn. (lychee), Mangifera indica L. (mango), Manilkara zapota L. (sapodila), Olea europeae L. (olive), Phoenix sylvestris (L.) Roxb. (date palm), Phyllanthus acidus L. (malay gooseberry), Psidium guajava L. (guava), Spondias mombin L. (golden apple/hog palm), Syzygiun cumini L. (java palm), Syzygium samarangense (Blume) Merr. and L.M. Perry (wax apple), Tamarindus india L. (tamarind), and Ziziphus jujube Mill. (jujube) were collected from the different parts of Bangladesh from January to December 2016. After the collection, edible parts of the fruits were separated and shed dried. Then, each dried sample was pulverized with a grinder machine and stored in air-tight containers at room temperature.

Ten grams of powder of each fruit was taken in a separate airtight bottle. Then, $200 \mathrm{ml}$ of methanol and ethanol mixture $(1: 1)$ was added to each bottle. The mixtures were vigorously shaken and kept at $30^{\circ} \mathrm{C}, 20 \mathrm{hrs}, 150 \mathrm{rpm}$. Then the mixtures were filtered through Whatman no. 1 filter paper and the filtrates were air-dried, and after adjustment of volumes, the extracts were kept in a refrigerator at $4^{\circ} \mathrm{C}$.

The total concentration of polyphenols (TP) in the extracts was determined according to the Folin-Ciocalteu's method (Ough and Amerine 1988) with gallic acid (GA) as the standard. The total flavonoids content (Zhishen et al. 1999), DPPH free radicals scavenging activity (Blois 1958), reducing power (Oyaizu 1986) and total antioxidant capacity (Prieto et al. 1999) were determined colorimetrically.

For AgNPs biosynthesis, $4 \mathrm{~g}$ of powder of each fruit was extracted with $80 \mathrm{ml}$ mixture of ethanol and methanol $(1: 1)$ and mixed thoroughly. The mixtures were incubated for $20 \mathrm{hrs}$ in a shaking incubator at $30^{\circ} \mathrm{C}$ and at $150 \mathrm{rpm}$. Then the supernatant was collected after centrifugation for $10 \mathrm{~min}$ at $3000 \mathrm{rpm}$. The collected supernatants were dried at room temperature and the volume was adjusted using distilled water.

Extract was mixed with $1 \mathrm{mM} \mathrm{AgNO}_{3}$ until the volume reached $2.5 \mathrm{ml}$. The mixture was incubated in dark in a shaking incubator for $20 \mathrm{hrs}$ at $30^{\circ} \mathrm{C}$ and $150 \mathrm{rpm}$. After incubation, absorbance was measured at $440 \mathrm{~nm}$ against blank using a spectrophotometer. The content of nanoparticles was expressed as optical density (OD).

Results were expressed as mean \pm SD (standard deviation) for a given number of observations, $n=3-5$. One-way analysis of variance was used to analyze the statistical difference. Differences with $\mathrm{p}<0.05$ were considered statistically significant. 


\section{Results and Discussion}

Total polyphenols content in these 35 fruits was found to range from 1.4 to $89 \mathrm{mg}$ GAE/g powder (Table 1). E. officinalis had the highest polyphenol content of $89 \mathrm{mg}$ GAE/g powder followed by G. cowa of $16.2 \mathrm{mg}$ GAE/g powder. Tsao (2010) reported that determining the amount of phenolic compounds is one of the effective ways to evaluate the total antioxidant properties of a given sample. Liu et al. (2008) and Agarwal et al. (2012) reported almost similar amount of polyphenols from E. officinalis fruits. Total flavonoids content of the fruits ranged from 0.6 to $17.3 \mathrm{mg} \mathrm{CE} / \mathrm{g}$ powder (Table 1). The highest flavonoids content was displayed by G. cowa (17.3 mg CE/g powder) which was followed by E. officinalis $(9.5 \mathrm{mg} \mathrm{CE} / \mathrm{g}$ powder). Flavonoids are a sub-class of polyphenols that should be less than the total amount of polyphenols but some fruits showed the opposite results because Folin-Ciocalteu method was unable to quantify all phenolic compounds from a complex mixture.

Among the fruits, A. reticulata, E. officinalis, G. cowa, P. sylvestris, P. guajava and S. cumini had more than $80 \%$ free radical scavenging activity at $0.5 \mathrm{mg}$ powder/ml (Table 1 ). Figure 1(A) showed dose-dependent scavenging of DPPH free radical by these potential fruits. The $\mathrm{IC}_{50}$ values for DPPH free radical scavenging of A. reticulata, E. officinalis, G. cowa, P. sylvestris, P. guajava and $S$. cumini were $180,21.8,172,188.9,162.4$ and $176.2 \mu \mathrm{g}$ powder/ml, respectively and that for ascorbic acid was $2.4 \mu \mathrm{g} / \mathrm{ml}$. E. officinalis showed the lowest $\mathrm{IC}_{50}$, which means that among these fruits it had the strongest DPPH scavenging activity. The $\mathrm{IC}_{50}$ values for DPPH free radical scavenging of mangrove fruits (Hosen et al. 2020), fruity vegetables (Hossain et al. 2014) and leafy vegetables (Hossain et al. 2015) were also reported. The highest reducing power, 1.98 (OD) was shown by E. officinalis at $1 \mathrm{mg}$ powder/ml followed by G. cowa (OD, 0.4) (Table 1). The strong reducing power of $E$. officinalis fruit might be due to the presence of the very high amount of polyphenols. The dose-dependent increase in the reducing power of the potential fruits is presented Fig.1B. Total antioxidant capacity was determined and expressed as both mg GAE/g powder and mg AAE/g powder (Table 1).
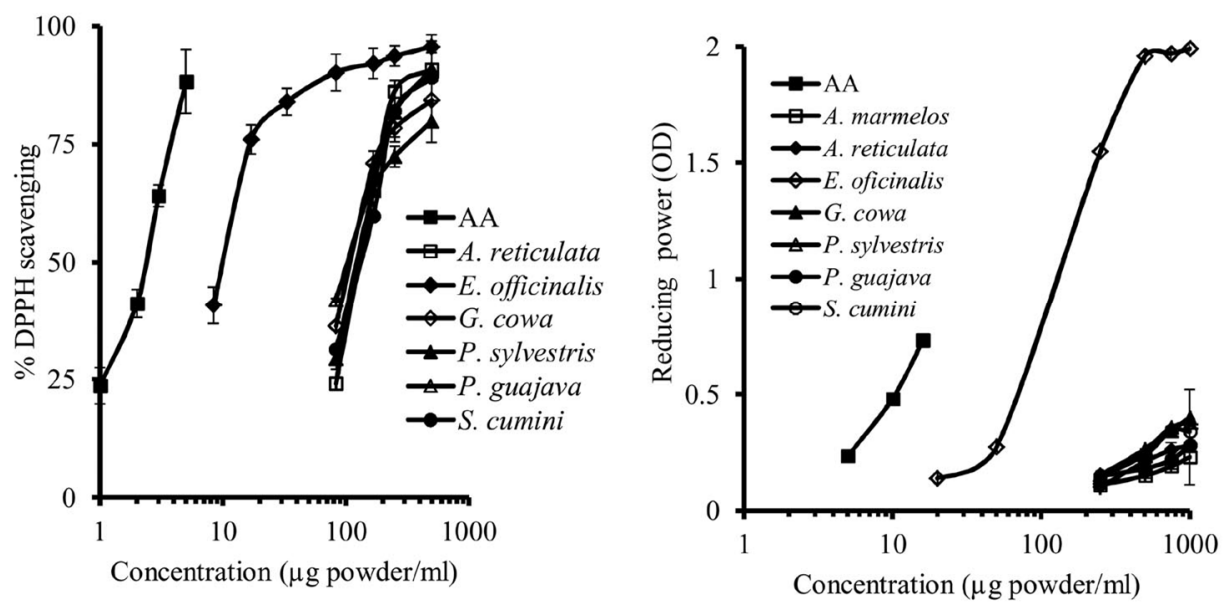

Fig. 1. Dose-dependent (A) DPPH free radical scavenging activity and (B) increase of reducing power of the potential fruits. $\mathrm{n}=3 \sim 5$; AA, ascorbic acid.

Figure 2 showed the potentiality of the fruits in the biosynthesis of AgNPs expressed as the mean of optical density (OD). P. guajava showed the highest potentiality (OD 0.74) in the biosynthesis of AgNPs followed by S. cumini (OD 0.68) and A. reticulata (OD 0.64) at $10 \mathrm{mg}$ 
Table 1. Polyphenols, flavonoids, DPPH scavenging, reducing power and total antioxidant capacity of the fruits.

\begin{tabular}{|c|c|c|c|c|c|c|}
\hline \multirow[t]{2}{*}{ Name of fruits } & \multirow{2}{*}{$\begin{array}{l}\text { Polyphenols } \\
\text { (mg GAE/g } \\
\text { powder) }\end{array}$} & \multirow{2}{*}{$\begin{array}{l}\text { Flavonoids } \\
\text { (mg CE/g } \\
\text { powder) }\end{array}$} & \multirow{2}{*}{$\begin{array}{l}\% \text { DPPH } \\
\text { scavenging at } \\
0.5 \mathrm{mg} \\
\text { powder } / \mathrm{ml}\end{array}$} & \multirow{2}{*}{$\begin{array}{l}\text { Reducing } \\
\text { power (OD) } \\
\text { at } 1 \mathrm{mg} \\
\text { powder/ml }\end{array}$} & \multicolumn{2}{|c|}{ Total antioxidant capacity } \\
\hline & & & & & $\begin{array}{l}\text { mg GAE/g } \\
\text { powder }\end{array}$ & $\begin{array}{l}\text { mg AAE/g } \\
\text { powder }\end{array}$ \\
\hline A. marmelos & $7.6 \pm 0.8$ & $3.2 \pm 0.2$ & $25.9 \pm 6.1$ & $0.23 \pm 0.02$ & $40.1 \pm 4.3$ & $17.3 \pm 2.2$ \\
\hline A. sativus & $4.8 \pm 0.5$ & $0.8 \pm 0.1 *$ & $22.6 \pm 4.2$ & $0.27 \pm 0.05$ & $65.1 \pm 6.9$ & $31.1 \pm 3.2$ \\
\hline A. reticulate & $12.2 \pm 0.6$ & $8.9 \pm 0.4$ & $90.9 \pm 9.3$ & $0.24 \pm 0.01$ & $54.7 \pm 3.7 *$ & $32.3 \pm 1.1$ \\
\hline A. heterophyllus & $2.7 \pm 0.6$ & $2.4 \pm 0.1$ & $13.3 \pm 0.8 *$ & $0.13 \pm 0.01$ & $32.7 \pm 3.1$ & $22.8 \pm 2.2$ \\
\hline A. lacucha & $1.5 \pm 0.1 *$ & $2.4 \pm 0.3$ & $0.1 \pm 0.1 *$ & $0.08 \pm 0.05^{*}$ & $17.2 \pm 1.1^{*}$ & $16.6 \pm 0.9$ \\
\hline A. bilimbi & $3.4 \pm 0.4$ & $3.3 \pm 0.5$ & $11.2 \pm 1.3^{*}$ & $0.16 \pm 0.05$ & $51.4 \pm 6.3$ & $32.8 \pm 3.4$ \\
\hline A. carambola & $4.6 \pm 0.4$ & $4.9 \pm 0.1$ & $13.9 \pm 2.7$ & $0.17 \pm 0.01$ & $60.9 \pm 5.1$ & $35.5 \pm 1.7$ \\
\hline B. ramiflora & $1.4 \pm 0.1^{*}$ & $0.7 \pm 0.2^{*}$ & $8.8 \pm 1.5^{*}$ & $0.06 \pm 0.01^{*}$ & $62.2 \pm 4.7$ & $44.3 \pm 2.7$ \\
\hline B. flabellifer & $1.6 \pm 0.1^{*}$ & $1.5 \pm 0.1$ & $7.7 \pm 1.3^{*}$ & $0.13 \pm 0.04$ & $25.6 \pm 1.5$ & $11.8 \pm 2.2$ \\
\hline C. papaya & $2.1 \pm 0.1$ & $1.4 \pm 0.1 *$ & $10.5 \pm 2.5 *$ & $0.18 \pm 0.02$ & $49.2 \pm 5.5$ & $30.7 \pm 3.2$ \\
\hline C. carandas & $6.3 \pm 0.6$ & $10.6 \pm 0.3$ & $57.1 \pm 4.8$ & $0.25 \pm 0.05$ & $23.7 \pm 3.2$ & $13.4 \pm 1.8$ \\
\hline C. aurantifolia & $3.6 \pm 0.5$ & $0.9 \pm 0.2 *$ & $23.5 \pm 3.7$ & $0.16 \pm 0.02$ & $21.1 \pm 4.1^{*}$ & $12.3 \pm 1.1$ \\
\hline C. maxima & $4.5 \pm 0.2$ & $1.5 \pm 0.1$ & $26.5 \pm 4.4$ & $0.15 \pm 0.06$ & $48.6 \pm 5.2$ & $35.3 \pm 2.9$ \\
\hline C. nucifera & $4.5 \pm 0.6$ & $9.3 \pm 0.6$ & $3.4 \pm 0.8^{*}$ & $0.15 \pm 0.02$ & $14.9 \pm 3.3^{*}$ & $10.3 \pm 1.2$ \\
\hline D. indica & $4.6 \pm 0.3$ & $2.3 \pm 0.1$ & $43.3 \pm 5.2$ & $0.17 \pm 0.04$ & $15.3 \pm 3.1^{*}$ & $11.2 \pm 1.3$ \\
\hline D. longan & $4.5 \pm 0.7$ & $1.5 \pm 0.1 *$ & $21.9 \pm 3.5$ & $0.21 \pm 0.02$ & $59.3 \pm 6.3$ & $41.7 \pm 3.6$ \\
\hline D. blancoi & $3.2 \pm 0.3$ & $0.7 \pm 0.1^{*}$ & $36.7 \pm 3.8$ & $0.14 \pm 0.05$ & $64.1 \pm 0.9$ & $52.4 \pm 4.2$ \\
\hline E. officinalis & $89.1 \pm 2.3$ & $9.5 \pm 0.4$ & $95.6 \pm 1.2$ & $1.98 \pm 0.07$ & $69.1 \pm 3.2$ & $47.4 \pm 3.1$ \\
\hline F. carica & $5.2 \pm 0.1$ & $3.5 \pm 0.2$ & $49.8 \pm 3.4$ & $0.14 \pm 0.02$ & $16.3 \pm 0.3^{*}$ & $10.6 \pm 0.2 *$ \\
\hline G. cowa & $16.2 \pm 2.7$ & $17.3 \pm 0.7$ & $84.3 \pm 0.2$ & $0.40 \pm 0.06$ & $52.9 \pm 4.5$ & $34.6 \pm 3.1$ \\
\hline L. acidissima & $4.1 \pm 0.2$ & $4.9 \pm 0.4$ & $12.3 \pm 2.2 *$ & $0.10 \pm 0.05^{*}$ & $34.5 \pm 5.8$ & $21.9 \pm 2.1$ \\
\hline L. chinensis & $4.9 \pm 0.1$ & $1.2 \pm 0.1^{*}$ & $31.2 \pm 4.4$ & $0.18 \pm 0.03$ & $79.1 \pm 7.5$ & $58.7 \pm 4.1$ \\
\hline M. indica (fazlee) & $4.1 \pm 0.2$ & $1.9 \pm 0.4$ & $61.5 \pm 4.8$ & $0.18 \pm 0.04$ & $29.1 \pm 4.1$ & $19.2 \pm 2.3$ \\
\hline M. indica (vuto) & $4.4 \pm 0.5$ & $2.5 \pm 0.4$ & $61.1 \pm 5.6$ & $0.19 \pm 0.04$ & $33.8 \pm 3.1$ & $22.3 \pm 2.3$ \\
\hline M. zapota & $1.9 \pm 0.3^{*}$ & $4.3 \pm 0.2$ & $10.2 \pm 1.4^{*}$ & $0.14 \pm 0.03$ & $48.3 \pm 4.5$ & $40.8 \pm 3.8$ \\
\hline O. europeae & $1.5 \pm 0.3^{*}$ & $0.6 \pm 0.1 *$ & $16.0 \pm 2.9$ & $0.11 \pm 0.05^{*}$ & $24.5 \pm 2.1$ & $11.9 \pm 2.9$ \\
\hline P. sylvestris & $10.7 \pm 0.7$ & $7.8 \pm 0.4$ & $80.8 \pm 8.5$ & $0.22 \pm 0.03$ & $56.3 \pm 6.6$ & $34.6 \pm 2.9$ \\
\hline P. acidus & $3.2 \pm 0.3$ & $1.3 \pm 0.1$ & $15.7 \pm 2.3$ & $0.17 \pm 0.02$ & $48.3 \pm 5.7$ & $29.1 \pm 2.7$ \\
\hline P. guajava & $7.9 \pm 0.4$ & $4.6 \pm 0.3$ & $90.9 \pm 0.9$ & $0.28 \pm 0.03$ & $58.3 \pm 3.6$ & $37.2 \pm 0.1$ \\
\hline S. mombin & $1.6 \pm 0.3^{*}$ & $0.9 \pm 0.2^{*}$ & $15.5 \pm 2.1$ & $0.09 \pm 0.05^{*}$ & $41.2 \pm 4.2$ & $24.3 \pm 2.6$ \\
\hline S. cumini & $10.5 \pm 1.2$ & $3.4 \pm 0.2$ & $89.1 \pm 0.9$ & $0.34 \pm 0.05$ & $66.2 \pm 3.4$ & $44.5 \pm 2.5$ \\
\hline S. samarangense (red) & $4.1 \pm 0.5$ & $1.1 \pm 0.1^{*}$ & $38.9 \pm 1.1$ & $0.18 \pm 0.06$ & $58.1 \pm 6.4$ & $36.6 \pm 2.6$ \\
\hline S. samarangense (white) & $3.1 \pm 0.4$ & $0.9 \pm 0.1^{*}$ & $26.1 \pm 1.9$ & $0.15 \pm 0.05$ & $55.9 \pm 5.6$ & $32.5 \pm 3.3$ \\
\hline T. indica & $3.2 \pm 0.3$ & $1.8 \pm 0.1$ & $31.6 \pm 7.0$ & $0.10 \pm 0.05^{*}$ & $11.7 \pm 4.9^{*}$ & $13.6 \pm 2.6$ \\
\hline Z. jujube & $6.7 \pm 0.9$ & $0.6 \pm 0.1 *$ & $21.1 \pm 3.8$ & $0.13 \pm 0.04 *$ & $43.9 \pm 1.2$ & $32.8 \pm 0.8$ \\
\hline
\end{tabular}

GAE, gallic acid equivalent; CE, (+)-catechin equivalent; DPPH, 2, 2-diphenyl-1-picrylhydrazyl; AAE, ascorbic acid equivalent. Values represent the mean $\pm \mathrm{SD}(\mathrm{n}=3 \sim 5)$. *indicates non-significant $(\mathrm{p}<0.05)$ through one way ANOVA when compared to control group.

powder/ml. Various metabolites existing in fruits including sugars, alkaloids, phenolic acids, terpenoids, polyphenols and proteins play an important role in the bioreduction of silver ions to AgNPs. Marslin et al. (2018) reported that polyol components, polysaccharides and water-soluble heterocyclic compounds were responsible for the reduction of silver ions and the stabilization of the produced nanoparticles. 


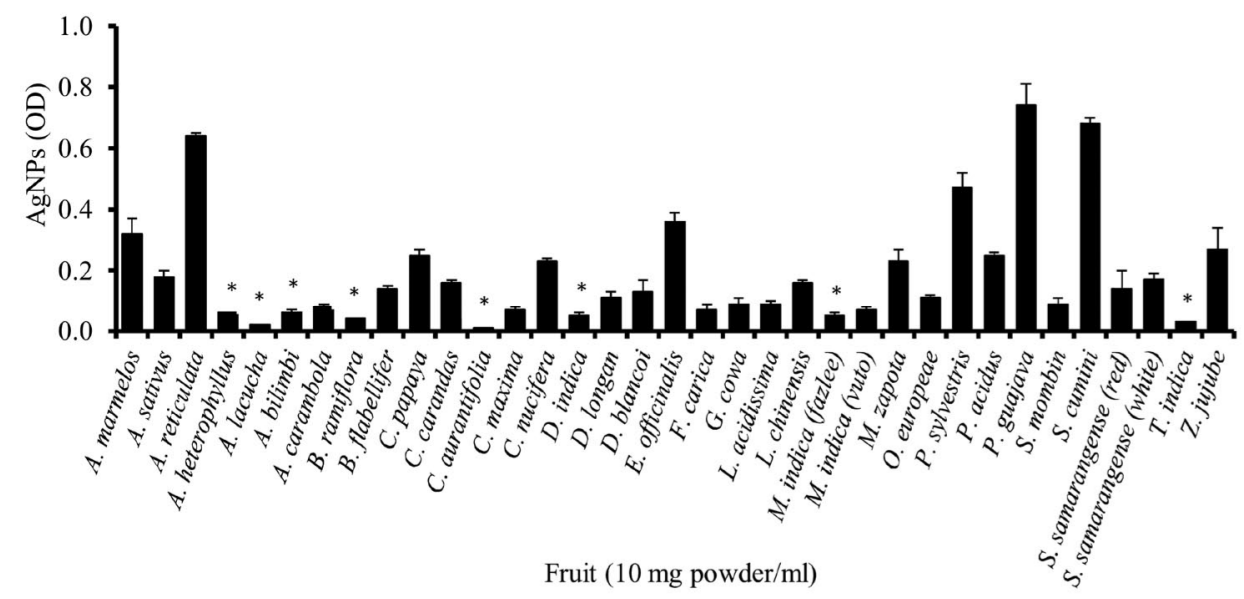

Fig. 2. Potentiality of the fruits in the biosynthesis of AgNPs. $n=3 \sim 5$; AgNPs, silver nanoparticles; OD, optical density. *indicates non-significant $(\mathrm{p}<0.05)$ through one way ANOVA when compared to control group.

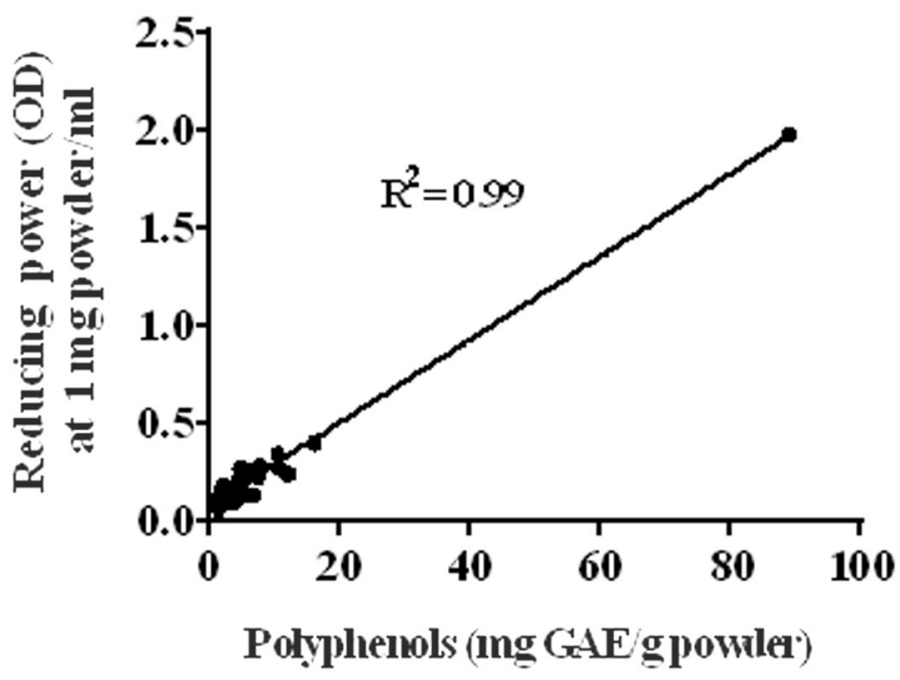

Fig. 3. Correlation of total polyphenols to reducing power of the fruits. $n=3 \sim 5$; GAE, gallic acid equivalent.

Total polyphenols content of these fruits showed strong correlation to reducing power $\left(\mathrm{r}^{2}=\right.$ 0.99) (Fig. 3). However, moderate correlation $\left(r^{2}=0.52\right)$ was found between total polyphenols and DPPH free radical scavenging. Hosen et al. (2020) also reported similar results for edible fruits in the Sundarbans' mangrove forest of Bangladesh. This moderate correlation might be due to the involvement of specific phenolic and non-phenolic compounds in scavenging DPPH free radicals. However polyphenols, the largest group of dietary antioxidants, are involved in the prevention of various metabolic and infectious diseases in humans. Since various polyphenols are used for the preparation of dietary supplements and functional foods, it is essential to determine their proper dose because some polyphenols perturb the membrane structure non-specifically (Hossain et al. 
2002). Among the 35 edible fruits, E. officinalis should be considered to be the best source of functional components and antioxidants followed by $S$. cumini, $P$. guajava, A. reticulata, $P$. sylvestris and G. cowa.

\section{Acknowledgments}

The research was supported by the Grant no. 37.20.0000.004.033.013.2015 dated 16.03.2016 from the Ministry of Education, Government of the People's Republic of Bangladesh. The authors gratefully acknowledged this funding.

\section{References}

Agarwal M, Kumar A, Gupta R and Upadhyaya S 2012. Extraction of polyphenol, flavonoid from Emblica officinalis, Citrus lemon, Cucumis sativus and evaluation of their antioxidant activity. Orient. J. Chem. 28: 993-998.

Ahmed S, Ahmad M, Swami BL and Ikram S 2016. A review on plants extract mediated synthesis of silver nanoparticles for antimicrobial applications: a green expertise. J. Adv. Res. 7: 17-28.

Blois MS 1958. Antioxidant determinations by the use of a stable free radical. Nature 181: 1199-1200.

Hekimi S, Lapointe J and Wen Y 2011. Taking a good look at free radicals in the aging process. Trends Cell Biol. 21: 569-571.

Hosen MZ, Biswas A, Islam MR, Bhuiyan MNI and Hossain SJ 2020. Comparison of physicochemical and antioxidant properties of edible fruits in the Sundarbans' mangrove forest, Bangladesh. Bangladesh J. Bot. 49: 671-678.

Hossain SJ, Basar MH, Rokeya B, Arif KMT, Sultana MS and Rahman MH 2013. Evaluation of antioxidant, antidiabetic and antibacterial activities of the fruit of Sonneratia apetala (Buch.-Ham.). Orient. Pharm. Exp. Med. 13: 95-102.

Hossain SJ, Islam MR, Pervin T, Iftekharuzzaman M, Hamdi OAA, Mubassara S, Saifuzzaman M and Shilpi JA 2017. Antibacterial, antidiarrhoeal, analgesic activities, and GC-MS profiling of Sonneratia apetala (Buch.-Ham.) seed. Prev. Nutr. Food Sci. 22: 157-165.

Hossain SJ, Kato H, Aoshima H, Yokoyama Y, Yamada M and Hara Y 2002. Polyphenol-induced inhibition of the response of $\mathrm{Na}^{+} /$Glucose cotransporter expressed in Xenopus oocytes. J. Agric. Food Chem. 50: 5215-5219.

Hossain SJ, Sultana MS, Iftekharuzzaman M, Hossain SA and Taleb MA 2015. A comparative study on antioxidant potential of common leafy vegetables in Bangladesh. Bangladesh J. Bot. 44: 51-57.

Hossain SJ, Sultana MS, Taleb MA, Basar MH, Sarower MG and Hossain SA 2014. Antioxidant activity of ethanol and lipophilic extracts of common fruity vegetables in Bangladesh. Int. J. Food Prop. 17: 20892099.

Hossain SJ, Tsujiyama I, Takasugi M, Islam MA, Biswas RS and Aoshima H 2008. Total phenolic content, antioxidative, anti-amylase, anti-glucosidase, and antihistamine release activities of Bangladeshi fruits. Food Sci. Technol. Res. 14: 261-268.

Kozyrev D and Slutsky V 2010. Handbook of free radicals: formation, types and effects. Hauppauge, NY, USA. pp. 57-59.

Liu X, Zhao M, Wang J, Yang B and Jiang Y 2008. Antioxidant activity of methanolic extract of emblica fruit (Phyllanthus emblica L.) from six regions in China. J. Food Comp. Anal. 21: 219-228.

Marslin G, Siram K, Maqbool Q, Selvakesavan RK, Kruszka D, Kachlicki P and Franklin G 2018. Secondary metabolites in the green synthesis of metallic nanoparticles. Materials 11: 1-25.

Ough CS and Amerine MA 1988. Methods for analysis of musts and wine. Wiley \& Sons, New York, pp. 196-221.

Oyaizu M 1986. Studies on products of browning reaction: antioxidative activity of products of browning reaction prepared from glucosamine. Jpn. J. Nutr. 44: 307-315. 
Prieto P, Pineda M and Aguilar M 1999. Spectrophotometric quantitation of antioxidant capacity through the formation a phosphomolybdenum complex: specific application to the determination of vitamin E. Anal. Biochem. 269: 337-341.

Tsao R 2010. Chemistry and biochemistry of dietary polyphenols. Nutr. 2: 1231-1246.

Zhishen J, Mengcheng T and Jianming W 1999. The determination of flavonoid contents in mulberry and their scavenging effects on superoxide radicals. Food Chem. 64: 555-559.

(Manuscript received on 10 October, 2020; revised on 31 July 2021) 